\title{
Analysis of molecular and clinical parameters of 4-year adalimumab therapy in psoriatic patients
}

\author{
Dominika Wcisło-Dziadecka1, Beniamin Grabarek ${ }^{2,3,4}$, Celina Kruszniewska-Rajs², Andrzej Swinarew ${ }^{5,6}$, \\ Krzysztof Jasik ${ }^{7}$, Beata Rozwadowska ${ }^{8,9}$, Agata Krawczyk ${ }^{10}$
}

${ }^{1}$ Department of Cosmetology, Faculty of Pharmaceutical Sciences in Sosnowiec, Medical University of Silesia in Katowice, Poland ${ }^{2}$ Department of Molecular Biology, Faculty of Pharmaceutical Sciences in Sosnowiec, Medical University of Silesia in Katowice, Poland ${ }^{3}$ Department of Histology, Cytophysiology and Embryology in Zabrze, Faculty of Medicine in Zabrze, University of Technology in Katowice, Poland

${ }^{4}$ District Hospital, Chrzanow, Poland

${ }^{5}$ Faculty of Science and Technology in Chorzow, University of Silesia in Katowice, Poland

${ }^{6}$ Department of Swimming and Water Rescue, Institute of Sport Science, The Jerzy Kukuczka Academy of Physical Education, Katowice, Poland

${ }^{7}$ Department of Pathology, Faculty of Pharmaceutical Sciences in Sosnowiec, Medical University of Silesia in Katowice, Poland

${ }^{8}$ Provincial Sanitary and Epidemiological Station, Katowice, Poland

${ }^{9}$ Silesian Medical College in Katowice, Poland

${ }^{10}$ Department of Nutrigenomics and Bromatology, Faculty of Pharmaceutical Sciences in Sosnowiec, Medical University of Silesia in Katowice, Poland

Adv Dermatol Allergol 2020; XXXVII (5): 736-745 DOI: https://doi.org/10.5114/ada.2020.100484

\begin{abstract}
Introdcution: Through interaction with receptors TNFR1 and TNFR2, TNF- $\alpha$ activates a signal path, which exacerbates an inflammatory process, constituting an inseparable element of psoriasis.

Aim: To evaluate changes in the expression of TNF- $\alpha$, TNFR1, TNFR2 during the 4-year-long adalimumab therapy in psoriatic patients, searching for the correlation between molecular and clinical markers. In addition, the role of miRNAs was analysed.

Material and methods: Whole blood and serum samples of psoriatic patients treated with adalimumab constituted material for the study. Changes in the expression of TNF- $\alpha$ and its receptors were evaluated with the use of the RTqPCR method and MALDI ToF mass spectroscopy, PASI, BSA, DAS28 indexes were used for the clinical analysis of the patients, while the role of miRNA molecules was determined basing on microrna.org database.

Results: Different TNF- $\alpha$ expression patterns were determined in patients with observed resistance to the medicine. We found that there is a correlation between the molecular markers of an inflammatory process and the clinical indexes. The bioinformatic analysis indicates the potential role of miRNAs in the regulation of expression of the analysed genes. Changes in the profile of TNF- $\alpha$ during adalimumab therapy are significantly determined by the individual variability and susceptibility to the biological medicine or its loss.

Conclusions: TNF- $\alpha$ seems to be a useful marker to evaluate the efficacy of therapy and occurring resistance to the medicine. A complex mechanism for the regulation of the analysed gene expression was underlined, which involved the potential role of miRNAs.
\end{abstract}

Key words: tumor necrosis factor $\alpha$, treatment personalisation, miRNA, anti-TNF therapy, psoriasis.

\section{Introduction}

The tumour necrosis factor $\alpha$ (TNF- $\alpha$ ) belongs to a superfamily of proteins. It is characterised by proinflammatory properties and plays an important role in the im- munologic response of human body [1-3]. It is generated by various types of cells, mainly the macrophages, monocytes, lymphocytes T and B, and synoviocytes. Two types of receptors for TNF- $\alpha$ are distinguished: TNFR1 and TNFR2 [2]. The first one is expressed in almost all nucle-

Address for correspondence: Assoc. Prof. Dominika Wcisło-Dziadecka MD, PhD, Department of Cosmetology, Faculty of Pharmaceutical Sciences, Medical University of Silesia, 3 Kasztanowa St, 41-200 Sosnowiec, Poland, phone/fax: +48 32 256 1182 , +48 3225915 80, e-mail: ddziadecka@sum.edu.pl Received: 5.02.2019, accepted: 14.03.2019. 
ated cells of human body, whereas the second receptor is expressed in fibroblasts, endothelial cells, lymphocytes, macrophages [1-5]. An interaction of TNF- $\alpha$ with receptors activates signalling cascades, the programmed cell death is activated when the ligand binds with TNFR1. In turn, receptor TNFR2 activates the cascade of the NF- $\kappa B$ path, inducing an inflammatory reaction in the cell [6].

Gene expression is strictly regulated on various levels, one of them being an epigenetic mechanism of the negative regulation of transcription by microRNA (miRNA) molecules. MiRNAs are short, about 23-nucleotide, noncoding fragments of RNA, regulating the expression of about $1 / 3$ of all human genes [7]. The role of miRNAs in the regulation of gene expression was studied by us with reference to the histaminergic role [8]. The role of these regulatory molecules is also emphasised in psoriasis $[9,10]$.

Psoriasis is a chronic, inflammatory skin disorder with complex immunopathogenesis [11]. TNF- $\alpha$ and the following interleukins (IL) play a significant role in psoriasis: IL-1, IL-6, IL-8, IL-12, IL-23. Their secretion is excessive and has an uncontrollable nature. TNF- $\alpha$ in psoriasis causes keratinocytes activation and their excessive proliferation. It is also responsible for an increased proliferation of $\mathrm{T}$ and $\mathrm{B}$ lymphocytes and their differentiation [11].

The anti-TNF therapy is one of the most efficient methods for treatment of proinflammatory diseases. Unfortunately, it also involves numerous undesirable effects $[12,13]$ and the occurrence of lost response to the medicine $[13,14]$.

Adalimumab is a fully-humanised human monoclonal antibody, showing ability to neutralise the TNF- $\alpha$, either in its membrane-related and soluble form, thus interrupting the signal path activated by the said cytokine. The efficacy of treatment measured with the use of PASI-75 index is over $60 \%$, in case of therapy lasting more than 60 weeks $[15,16]$.

\section{Aim}

The aim of the study is to evaluate the expression of TNF- $\alpha$ and its receptors TNFR1 and TNFR2, and the role of the epigenetic mechanism - the miRNA molecules in the regulation of expression of the analysed genes in patients treated with anti-TNF adalimumab during the 4-year-long observation. The correlation between molecular markers and disease progression indexes or its absence was also evaluated.

\section{Material and methods}

Whole blood and serum of patients treated with adalimumab (2 women - patients $A$ and $B$, and 5 men - patients C, D, E, F, G), aged $47.2 \pm 9.86$ years, with diagnosed psoriatic arthritis, who gave their informed consent to the study, constituted the material used for the tests. Patient A was monitored within the dose range: 11-94 (42 months), B - 23-103 (39 months), C - 25-96 (42 months), D - 6-94 (39 months), and E - 31-105 (36 months). The monitoring time of patients $F$ ( 15 months) and $\mathrm{G}$ (3 months) was shorter than the time of monitoring the other patients due to the fact that patients $\mathrm{F}$ and $\mathrm{G}$ lost their response to the adalimumab therapy. The clinical and molecular characteristics of those $2 \mathrm{pa}-$ tients during their adalimumab therapy were only taken into account. The material used for the study was taken from patients every 12 weeks. The blood was taken before the administration of a next dose of the medicine and $2 \mathrm{~h}$ after its administration, which constituted one monitoring session for each patient. Each patient was given adalimumab at a concentration of $40 \mathrm{mg}$ every 2 weeks. Molecular and clinical assessment was performed every 12 weeks.

The control group consisted of 20 people ( 9 women and 11 men), aged $46 \pm 10$ years, who gave their voluntary consent to the study by signing the informed consent forms. The volunteers were healthy persons, who did not suffer from psoriasis or other skin diseases and who had not used any corticosteroids during the 3 months preceding their participation in the research project.

The first stage of the molecular analysis involved isolation of total RNA from the whole blood with the use of FENOZOL reagent (A\&A Biotechnology, Gdańsk, Poland), according to the guidelines included in the protocol. Extracts of nucleic acid were then quantitatively assessed through electrophoresis in $0.8 \%$ agarose gel, and also qualitatively by means of spectrophotometry (GeneQuant II, Pharmacia Biotech).

The next stage of the molecular analysis involved the qualitative amplification reaction with reverse transcription (RTqPCR) for mRNA for the following genes: TNF- $\alpha$, TNFR1, TNFR2 in the presence of $\beta$-actin (ACTB), as a control of endogenous reactions. The reaction was conducted with the use of pairs of starters specific for the sequence of each tested gene. Oligonucleotide sequences of starters used for gene amplification: TNF- $\alpha$ (forward: 5'CTCAAGCTGAGGG GCAGCTCC-3', reverse: 5'-TGGGTGAGGAGCACATGGGTG-3'), TNFR1 (forward: 5'-CACCACAGTGCTG TTGCCCCT-3', reverse 5'-TGGAGTGGGACTGAAGCTT GGG-3'), TNFR2 (forward 5'-AGTATGGCCCCAGGGGCAGTACA-3', reverse 5'-TCTCTCTGCAGGCACAAGGGCTT-3'), ACTB (forward 5'-TCACCCACACTGTGCC CATCTACGA-3', reverse 5'-CAGCGGAACCGCTCATTGCCAATGG-3'). The RT-qPCR reaction was conducted with the use of the Opticon ${ }^{\text {TM }}$ DNA Engine Sequence Detector (MJ Research Inc., Watertown, MA, USA), with the use of the SYBR Green Quantitect RTPCR Reagent Kit (Qiagen, Valencia, CA, USA), according to the producer's recommendations. The thermal profile of the reaction was as follows: reverse transcription: $50^{\circ} \mathrm{C}$ for $30 \mathrm{~min}$, polymerase activation: $95^{\circ} \mathrm{C}$ for $15 \mathrm{~min}$, 40 cycles composed of the following stages: denatur- 
ation: $94^{\circ} \mathrm{C}$ for $15 \mathrm{~s}$, starters activation: $53.3^{\circ} \mathrm{C}$ for $30 \mathrm{~s}$, prolongation: $72^{\circ} \mathrm{C}$ for $45 \mathrm{~S}$.

For the detection of the TNF cytokine in the serum, the MALDI ToF mass spectroscopy was used, supported by a matrix due to an exceptionally smooth ionisation. It excludes the possible damage of the analysed proteins. The MALDI-ToF2-MS2 AXIMA Performance spectrometer (matrix assisted laser desorption ionisation - timeof-flight mass spectrometry) was used for the analysis (Shimadzu; Kyoto, Japan). The analysis was performed in the linear and reflectron modes, with the accelerating voltage of $20 \mathrm{kV}$. The spectrometer was calibrated with the use of a standard ProteoMass Peptide MALDI-MS Calibration Kit (Sigma-Aldrich, St. Louis, MO, USA). The 2,5-dihydroxybenzoic acid was used as a matrix (SigmaAldrich). The samples were mixed with a relevant matrix $1: 1$, and then placed on an analytic table, in the amount of $1.5 \mu \mathrm{l}$ per measuring point on a graphite base in order to facilitate ionisation, thanks to quick rupture of the Van der Waals bonds. Each sample was analysed thrice in order to minimise the device error. Acquired mass spectra were analysed with the use of MALDI - MS software (Shimadzu Biotech Launchpad 2. 93 20110624). Prior to the commencement of the analysis involving the samples used for the study, the mass spectrum of the TNF standard was characterised with the use of MALDI ToF mass spectrometry, which allowed to select a relevant column for the gel and liquid chromatograph.

Basing on the bioinformatic databases (www.microrna.org), potential miRNAs were selected which could regulate the expression of analysed transcripts. The miRanda-mirSVR algorithm, constituting a combination of the miRanda and mirSVR procedures, was used to find the relevant miRNA molecules. By using this algorithm, it is possible to select a target mRNA for a relevant miRNA (miRanda) molecule and determine a correlation between them (mirSVR). The analysis is performed on the basis of the following: A SEEDMATCH, conservativeness, free enthalpy and the availability of sequence of the selected miRNA molecule.

Consent of the Bioethics Commission of the Medical University of Silesia in Katowice/Poland no. KNW/0022/ KB1/59/I/13/14.

\section{Statistical analysis}

The statistical analysis was performed with the use of Statistica 12.0 PL software (StatSoft, Tulsa, Oklahoma, USA), assuming the statistical gravity factor $p<0.05$. We searched for the Spearman's rank correlation between the TNF- $\alpha$ expression profile and the clinical parameters (PASI, BSA, DAS28) and between each of these for each patient. The possible correlation between expressions of the three genes analysed in this study for each patient was also assessed.

\section{Results}

The transcription activity of the genes under study was presented as the number of mRNA copies of the gene: TNF- $\alpha$, TNFR1, TNFR2, converted into $1 \mu \mathrm{g}$ of total RNA.

Changes in the expression profiles of mRNA and selected clinical parameters (PASI, DAS28, BSA) in each patient during the 4-year-long observations were presented in Table 1. Due to a vast amount of data, Table 1 includes only the most significant data.

The transcription activity of genes in the form of the numbers of transcript copies/1 $\mu$ g of total RNA (mean \pm standard deviation) was determined in comparison to the control group, composed of healthy volunteers: TNF$(1149048 \pm 1554419)$, TNFR1 (547826 \pm 777004$)$, TNFR2 $(1037 \pm 1731)$.

When making a general comparison, it may be noted that in the study group, the TNFR1 expression is lower than in the control group, however, the TNFR2 expression in the group treated with adalimumab is higher than in the group composed of healthy volunteers. A higher expression of $T N F-\alpha$ is also observed in the group treated with the medicine, when compared with the control group.

Expression profiles of TNF- $\alpha$ and its receptors were evaluated during the therapy for each patient individually. In general, the period during which the changes in the transcription activity of analysed genes were monitored corresponds to 15 or 16 monitoring sessions, during the period of 4 years; only in case of patient $E$, the therapy monitoring time for the needs of the study covered 13 monitoring sessions. For patients $F$ and $G$, the changes in the transcription activity of analysed genes and the clinical characteristics were presented only during the adalimumab therapy. Then, these patients proceeded to be treated with etanercept.

When comparing the TNF- $\alpha$ expression in the control group and the group under study, a higher expression of the transcript may be observed in the control group. The situation is similar in case of TNFR1. In turn, in case of TNFR2, some patients (A, B, C, F, G) generally show a higher expression of this gene when compared with the control group, whereas in patients $D$ and $E$, the TNFR2 transcript activity is lower than in the control group, except for some rare exceptions.

As far as patient $A$ is concerned, there occurs no regularity in TNF- $\alpha$ expression concerning a lower expression after administration of the next dose of the medicine. Most often, $2 \mathrm{~h}$ after administration of the next dose of medicine, an increased transcription activity of the analysed gene may be observed, when compared with the expression measured in time before drug administration. Nevertheless, the level of TNF- $\alpha$ expression during the $6^{\text {th }}$ monitoring session after administration of the medicine to patient $A$ is zero. Such level of expression lasts for the next two $\left(7^{\text {th }}\right.$ and $\left.8^{\text {th }}\right)$ monitoring sessions, either before and after 
Table 1. The most significant data of molecular and clinical characteristics of patients A-G treated with adalimumab

\begin{tabular}{|c|c|c|c|c|c|c|}
\hline \multirow[t]{2}{*}{ Monitoring } & \multicolumn{3}{|c|}{ mRNA [copy/ug RNA] } & \multicolumn{3}{|c|}{ Clinical parameters } \\
\hline & TNF- $\alpha$ & TNFR1 & TNFR2 & PASI & BSA & DAS28 \\
\hline \multicolumn{7}{|l|}{ Patient A: } \\
\hline I & 0 & 0 & 0 & 10.4 & 25 & 3.02 \\
\hline IV & 8610 & 7287 & 2279333 & 9 & 16 & 2.44 \\
\hline VIII & 0 & 0 & 0 & 3 & 15 & 4.05 \\
\hline XII & 28267 & 31422 & 39 & 7 & 17 & 3.23 \\
\hline $\mathrm{XVI}$ & 28 & 0 & 168 & 5 & 9 & 3.84 \\
\hline \multicolumn{7}{|l|}{ Patient B: } \\
\hline 1 & 0 & 0 & 0 & 4 & 21 & 2.48 \\
\hline IV & 0 & 0 & 176519 & 4.8 & 4 & 3.09 \\
\hline VIII & 37824 & 76784 & 75 & 2 & 8 & 3.6 \\
\hline$x V$ & 358 & 0 & 1746 & 15 & 15 & 4.29 \\
\hline \multicolumn{7}{|l|}{ Patient C: } \\
\hline I & 10 & 0 & 0 & 18 & 31 & 2.62 \\
\hline VII & 40595153 & 0 & 189121 & 5 & 10 & 3.09 \\
\hline XIV & 307 & 5 & 11011 & 5 & 10 & 3.02 \\
\hline$x V$ & 0 & 0 & 479 & 5 & 10 & 3.55 \\
\hline $\mathrm{XVI}$ & 30591 & 0 & 94545 & 5 & 8 & 2.61 \\
\hline \multicolumn{7}{|l|}{ Patient D: } \\
\hline I & 0 & 0 & 334 & 2.7 & 10 & 3.58 \\
\hline III & 0 & 513500 & 2535 & 2 & 4 & 3.11 \\
\hline VII & 42477370 & 0 & 188 & 3.3 & 4 & 2.38 \\
\hline$x V$ & 16 & 0 & 1509 & 3 & 3 & 2.95 \\
\hline \multicolumn{7}{|l|}{ Patient E: } \\
\hline 1 & 5650 & 57 & 19920 & 18 & 26 & 5.86 \\
\hline VII & 0 & 0 & 37912 & 7 & 12 & 4.61 \\
\hline XII & 0 & 0 & 0 & 6 & 11 & 4.82 \\
\hline XIII & 0 & 0 & 0 & 6 & 11 & 2.84 \\
\hline \multicolumn{7}{|l|}{ Patient F: } \\
\hline 1 & 0 & 0 & 0 & 13 & 50 & 5.18 \\
\hline V & 275633 & 168333 & 144 & 3.8 & 8 & 4.08 \\
\hline $\mathrm{VI}$ & 0 & 0 & 312284593 & 9.6 & 15 & 4.48 \\
\hline \multicolumn{7}{|l|}{ Patient G: } \\
\hline 1 & 0 & 14 & 329 & 5.7 & 30 & 4.27 \\
\hline ॥ & 1598 & 53300 & 58950 & 14 & 31 & 3.77 \\
\hline
\end{tabular}

medicine administration. Additionally, during these two periods, apart from improved molecular parameters, improvement in the clinical condition can also be observed, which is confirmed by results of clinical parameters. Moreover, immediately after these drug administrations, a situation may be observed in which TNF- $\alpha$ expression before drug administration is higher than after it. Additionally, during the observation at the $13^{\text {th }}$ monitoring session a clinical improvement was ascertained, which is confirmed by the obtained result of expressions of the analysed three transcripts. With reference to receptor expressions, a greater number of transcripts of the $2^{\text {nd }}$ receptor is observed when compared with the $1^{\text {st }}$ receptor during the first and last period of the patient's observations, whereas between them ( $9^{\text {th }}-12^{\text {th }}$ monitoring sessions), the situation is opposite to the one described. 
In patient $B$, initially no expression in RNA TNF- $\alpha$ is observed, however, the situation changes during the $3^{\text {rd }}$ monitoring session, after administration of the next dose. A relatively increased TNF- $\alpha$ expression - with reference to patient $B$ - is observed during the $9^{\text {th }}$ and $10^{\text {th }}$ monitoring sessions. At the same time, in the case of these particular sessions, it was observed that the activity of the analysed transcript is lower after adalimumab administration, when compared with its level before drug administration. Generally, apart from rare exceptions, TNFR2 expression is at the higher level when compared with TNFR1, for which the expression is indeterminable.

A lower TNF- $\alpha$ expression cannot be always observed in patient $C$ after administration of the next dose of the medicine. Initially, the expression of the discussed gene - observed at the relatively low level - increased, which is the most visible during the $18^{\text {th }}$ and $9^{\text {th }}$ monitoring sessions, to reach - for some time - the level similar to that observed at the beginning of the monitoring process. Basically, during the whole observation period, a higher quantity of TNFR2 transcripts are noted, when compared to TNFR1.

When analysing the TNF- $\alpha$ expression profile for patient $D$, three basic types can be distinguished: the first one between the $1^{\text {st }}$ and $6^{\text {th }}$ monitoring sessions, where the expression is relatively low, the second between $7^{\text {th }}$ and $8^{\text {th }}$, where the activity level is the highest, though the decreasing trend can be noted during the $12^{\text {th }}$ monitoring, which is - similarly as during the third stage - the best observed during the $14^{\text {th }}$ and $15^{\text {th }}$ monitoring sessions. During the highest TNF- $\alpha$ expression, it can be observed that TNFR1 expression is greater than TNFR2 expression, though the opposite phenomenon is observed during the remaining period.

Patient E was monitored for the shortest period among all patients. Out of all patients, the TNF- $\alpha$ expression level was the lowest in that patient. In almost half of the monitoring sessions for patient $\mathrm{E}$, the expression of analysed gene mRNA is 0 copies/1 $\mu$ g RNA. Moreover, only for that patient no expression was ascertained for both receptors $\left(3^{\text {rd }}, 10^{\text {th }}-13^{\text {th }}\right)$. In the remaining period of the observation, TNFR2 expression was higher than TNFR1, as for the other patients.

Clinical and molecular observation for patients $F$ and $G$ covered, $6^{\text {th }}$ and $2^{\text {nd }}$ monitoring sessions, respectively, which was connected with the patients' no response to medicine. Further treatment is continued in these patients also basing on the anti-TNF- $\alpha$ therapy (etanercept).

During the first and last monitoring sessions, no TNF- $\alpha$ transcription activity was observed in patient $F$, however, in the remaining period of the observation the gene expression was noted. Expression of genes encoding TNFR1 and TNFR2 receptors may also be observed. The quantity of mRNA copies of gene TNFR2 was higher in comparison to TNFR1. In case of patient G, the observation period involved two monitoring sessions, during which changes in the profiles of three analysed genes were noted.

The analysis of TNF- $\alpha$ expression on the proteome level in patients $(A, B, C, D, E, F)$ showed total inhibition of expression, with the level of TNF- $\alpha$ concentration in the patients' serum of $0 \mathrm{pg} / \mathrm{ml}$. However, patient $\mathrm{G}$ had the TNF- $\alpha$ protein ascertained at the level of - before drug administration - $17 \mathrm{pg} / \mathrm{ml}, 2 \mathrm{~h}$ after drug administration $-47 \mathrm{pg} / \mathrm{ml}$, during the $2^{\text {nd }}$ monitoring session.

The next part of the experiment described in this study involved the analysis of a possible presence of statistically significant $(p<0.05)$ Spearman's rank correlation rs (due to the fact that there is no regular data factorisation) between TNF- $\alpha$ expression and disease clinical progression indexes (PASI, BSA, DAS28) for each patient and the relationships between the individual indexes. A positive value of the correlation indicates that an increased value of one parameter involves an increase in another. In turn, a negative value shows that an increased value of one parameter corresponds to a lower value of the other analysed parameter. The strongest the dependence between the analysed factors, the higher value of the correlation.

On the basis of the performed analysis, we observed statistically significant correlations between PASI and BSA indexes (patient A: $r s=0.6282408$ - moderate correlation; patient $\mathrm{B}$ : $r s=0.530327$ - moderate correlation; patient C: rs $=0.806779$ - strong correlation; patient E: rs $=0.896611$ - strong correlation; patient F: $r s=0.942857$ - very strong correlation), between PASI and DAS28 for patient C rs $=-0.551763$ - moderate correlation; for patient F rs $=0.828571$ - very strong correlation).

A statistically significant correlation was observed in TNF- $\alpha$ expression and DAS28 (in patient D rs $=-0.544785$ - moderate correlation) and between TNF- $\alpha$ expression and PASI (in patient Frs $=-0.811679$ - strong correlation).

Except for patient $\mathrm{G}$, a positive - moderate to strong correlation was observed between TNF- $\alpha$ expression and TNFR1 (patient A rs $=0.764493$, patient B rs $=0.452934$, patient C rs $=0.460081$, patient D rs $=0.489495$, patient $\mathrm{E} r \mathrm{~s}=0.568689$, patient F $r s=0.884058$ ). Additionally, the correlation between TNF- $\alpha$ expression and TNFR2 $r s=0.539056$ was observed in patient $E$.

The last part of the study focused on whether the expression of analysed genes: TNF- $\alpha$, TNFR1, TNFR2 involves an engagement of the epigenetic mechanism of gene regulation. To this end, it was determined, in silico, which miRNA molecules might potentially post-transcriptionally regulate expression of the analysed genes, using the value mirSVR $\leq-0.8$ as a cutting point - as the indicator of the potential effect of miRNA on gene expression (Table 2).

The in silico analysis, in reference to TNF- $\alpha$, made it possible to observe that its transcription activity may be regulated by 39 miRNA molecules, but only 13 miRNAs complied with the criterion mirSVR score $\leq-0.8$. In turn, 
TNFR1 expression is regulated by 9 miRNAs, but only 1 miRNA (hsa-miR-335) complied with the assumed cutoff criterion for mirSVR score $\leq-0.8$. In case of TNFR2, it was ascertained that its transcription activity may be regulated by 26 miRNAs, but only 1 miRNA (hsa-miR-495) complies with the criterion mirSVR score $\leq-0.8$ (Table 2).

\section{Discussion}

Within the framework of this study, the changes in the expression of TNF- $\alpha$ and its receptors TNFR1 and TNFR2 were analysed at the level of MRNA and proteins in patients qualified for therapy with the use of an anti-TNF medicine: adalimumab. Changes in the expression profile of the analysed genes in each patient were analysed individually and then summarised jointly for each patient, with the following clinical parameters: PASI, DAS28, BSA, enabling the phenotypic assessment of the patients.

Personalisation of therapy and individual treatment of each patient constitute important and essential issues. The answer to this aspect of diagnostics and treatment is the '4P medicine' - predictive, personalized, preventive and participatory medicine [17]. Consequently, despite the fact all patients received the same medicine, in the same dose and were monitored at the identical time intervals, in the authors' opinion, the response to the applied treatment should be analysed individually. Personalisation of medicine increases the number of therapeutic strategies and makes it possible to decrease the number of undesirable effects $[13,18-20]$. In this respect, understanding of molecular aspects of a given disease, a response to treatment, knowing and understanding of mechanisms relating to response to applied pharmacotherapy become important issues.

With reference to the analysis of changes in the transcription activity of TNF- $\alpha$ in patients A-D, basically, it was observed that three periods can be distinguished during the monitoring of the efficacy of the therapy: a relatively low level of expression of the analysed gene, a sudden and relatively increased expression, followed by a reduced expression. All 4 patients show a little TNF- $\alpha$ expression in the initial period of molecular monitoring and not very large expression between the individual periods of observation. Next, an increased expression can be observed that lasts for some time during treatment observation, only to proceed to the reduced expression of the gene encoding TNF- $\alpha$, compared to the observed level. Moreover, during the second stage of the observation, during the increased TNF- $\alpha$ expression, it was noted that TNFR1 expression is higher than TNFR2 expression, which is an opposite situation to the one observed at the lower level of $T N F-\alpha$, where the transcription activity of TNFR1 is lower than TNFR2 expression. In the first and last periods of monitoring, the efficacy of therapy, TNFR1 expression is observed at the level of 0 copies $/ 1 \mu \mathrm{g}$ RNA or on the similar level. TNFR1 is expressed through
Table 2. A list of miRNAs potentially regulating the expression of genes: TNF- $\alpha$, TNFR1, TNFR2 (microrna.org). The value criterion mirSVR $\leq-0.8$

\begin{tabular}{lll}
\hline mRNA & $\begin{array}{c}\text { miRNA potentially } \\
\text { regulating expression }\end{array}$ & mirSVR score \\
\hline TNF- $\alpha:$ & & \\
\cline { 2 - 3 } & hsa-miR-599 & -0.8380 \\
\cline { 2 - 3 } & hsa-miR-130a & -1.1947 \\
\cline { 2 - 3 } & hsa-miR-130b & -1.1964 \\
\hline & hsa-miR-454 & -1.1996 \\
\hline & hsa-miR-301a & -1.1996 \\
\cline { 2 - 3 } & hsa-miR-301b & -1.1996 \\
\hline hsa-miR-19b & -1.0508 \\
\hline hsa-miR-19a & -1.0708 \\
\hline hsa-miR-181a & -1.2770 \\
\hline hsa-miR-181b & -1.2770 \\
\hline TNFR1 & hsa-miR-181c & -1.2789 \\
\hline hsa-miR-181d & hsa-miR-150 & -1.2779 \\
\hline & hsa-miR-335 & -1.0833 \\
\hline & hsa-miR-495 & -0.9038 \\
\hline
\end{tabular}

the majority of nucleated cells and, due to its embedded death domain, it participates mainly in the apoptosis of cells, whereas TNFR2 expression is observed only on the surface of specific cells and it is engaged mainly in the induction of $\mathrm{T}$ lymphocyte proliferation [21, 22]. An increased TNF- $\alpha$ expression observed by us, accompanied by an increased number of TNFR1 transcript copies may suggest an escalation of proapoptotic processes, being the consequence of the lost response of cells to the antiTNF medicine. On the other hand, it should be taken into account that intensified TNF- $\alpha$ secretion may not necessarily be triggered by the occurring lost response to the drug, but it may be a result of an interferon- $\gamma$ effect (IFN- $\gamma$ ) [23], which intensifies TNF- $\alpha$ secretion as well as induces receptor expression for TNF- $\alpha[24,25]$.

A different expression profile is present in patient $\mathrm{E}$ - the highest TNF- $\alpha$ expression is observed at the beginning of the molecular treatment, then, during next stages of the observation, the expression is relatively low (when compared with that observed at the very beginning) or amounts to 0 copies/1 $\mu$ g RNA. Moreover, patient E shows a different profile of TNFR1 and TNFR2 expression, compared with the other 4 patients. In the vast majority, the expression profile remains at the level of 0 copies RNA/1 $\mu g$ RNA.

In turn, patients $F$ and $G$ lost their response to treatment after some time following its commencement. These patients show, clinically, relatively low changes in the values of parameters describing intensity and advancement of changes (PASI, BSA, DAS28) and gradually 
increasing values of the said parameters. Moreover, the TNF- $\alpha$ expression in 1 patient was observed not only at the transcriptome level, but also at the proteome level. Although at the moment of making a decision to discontinue the anti-TNF therapy in patient $F$, the cytokine expression level amounts to zero, yet in the previous monitoring periods TNF- $\alpha$ expression is observed, which seems to confirm that molecular changes precede the phenotypic changes [13].

Individual differences in the expression of analysed phenotypes in patients subject to the same pharmacotherapy constitutes another premise for a personalised treatment and an individual approach towards each patient. Moreover, one should not forget about the individual variability, a various speed of drug metabolization by individual patients $[26,27]$. During the studies conducted by Czarnecka et al., a higher percentage of persons classified as 'quick metabolizers' was observed among psoriatic patients (common psoriasis). The researches indicate a higher risk of disease development $(O R=1.22)$ in quick metabolizers, when compared with persons with a slow and moderate CYP2D6 genotype [28]. One should also take into account the possible presence of antibodies directed against adalimumab [29-31]. The possible occurrence of the aforementioned regularities may be linked with the fact that we have observed no similar, permanent level of TNF- $\alpha$ expression between the individual periods of molecular and clinical parameters evaluation. It is visible with regard to 1 patient, but the differences of such type can also be observed between the individual patients.

The efficacy of therapy with the use of adalimumab is also confirmed by the data from other centres, which also emphasise the immunogenicity of the medicine in comparison with other drugs from the anti-TNF blockers group [16, 32, 33]. In our studies, it may also be observed that TNF- $\alpha$ expression at the mRNA level often remains at the low, frequently zero level, relatively after an administration of just a few doses of the medicine (monitoring commencement). Then, as it was already mentioned, the number of transcript copies increase, however, the prolonged period of drug administration leads to a lower expression, because TNF- $\alpha$ is bound and neutralised by adalimumab. Changes in the receptor expression profiles are observed at that time, which may result from the fact that there is no cytokine which could bind with receptors and initiate the signal cascade.

The efficacy of the anti-TNF- $\alpha$ therapy is reflected by the fact that we observed lower TNF- $\alpha$ transcription activity in patients treated with adalimumab than in the control group. Studies conducted by Shveta et al. confirm the TNF- $\alpha$ role in psoriasis pathogenesis and, when compared with our own studies, they confirm the efficacy of an anti-TNF medicine therapy. They observed a higher level of TNF- $\alpha$ in the group of psoriatic patients before treatment when compared with healthy persons. During the therapy with the use of coal tar $(6 \%)+$ dithranol + salicylic acid (3\%), these researchers observed lower concentrations of TNF- $\alpha$ proteins in patients [34].

In our work, on the basis of the statistical analysis performed, we proved the correlation between TNF- $\alpha$ expression, PASI and BSA in 2 patients. Both correlations were negative, which means that increased TNF- $\alpha$ should correspond to expected decreased values of the said clinical indexes. Our observations vary from those of Shveta et al. [34], who observed in psoriatic patients, following their therapy, lower PASI values and TNF- $\alpha$ concentrations. Nevertheless, one should bear in mind that a different form of therapy was used and that the PASI values in the said paper were compared with TNF- $\alpha$ expression at the proteome level. In turn, Serefican et al. also ascertained a higher level of TNF- $\alpha$ expression in the group of psoriatic patients, when compared with the control group and observed a statistically significant positive correlation between TNF- $\alpha$ expression and PASI. However, one should take into account that the analysis of cytokine expression was made at the protein level and that the patients were not then subject to any anti-psoriasis therapy [35]. Consequently, the fact that we noted a negative regulation may indicate the complex mechanism of adalimumab action.

In addition, the strength of the correlation remains within the range from moderate to strong. Moreover, statistically significant correlations were observed between PASI and BSA values as well as between PASI and DAS28, where the correlation was not lower than moderate and the direction of changes - positive. It would confirm the usefulness of the afore-mentioned parameters to examine and analyse the degree of lesion advancement in psoriatic patients. The correlation between the TNF- $\alpha$ and TNFR1 expression profiles were also noted (in 6 patients) and between TNF- $\alpha$ and TNFR2 (in 1 patient).

The fact that no TNF- $\alpha$ expression was observed at the proteome level $(0 \mathrm{pg} / \mathrm{ml})$, while it was observed at the transcript level made the authors of this publication evaluate the epigenetic mechanism of gene expression. The post-transcriptional mechanism of the gene expression regulation is based on RNA interference, that is why miRNAs play a crucial role in it $[7,8]$. Basing on the bioinformatic databases microrna.org, the search was made whether, and - if so - which miRNAs are potentially capable of regulating TNF- $\alpha$, TNFR1, TNFR2 expressions, and - consequently - inhibiting the TNF- $\alpha$ expression at the protein level.

The occurrence of TNF- $\alpha$ expression at the protein level was observed only in 1 patient treated with adalimumab, who was classified to change his treatment strategy because of his lost response to therapy. Two hours after the administration of another drug dose, a higher concentration of protein was observed in this patient than before the anti-TNF medicine administration, what was also reflected at the transcriptome level. 
The observed expression of TNF- $\alpha$ at the protein level in one of the patients who lost their response to the therapy may also suggest the effect of adalimumab also on the post-transcriptional stage of gene expression regulation. However, the authors of the publication hereto cautiously formulate and generalise such kind of conclusions, due to the relatively small group covered by the study and its low diversification.

Though the miRNAs for which the values of mirs$V R \leq-0.1$ are capable of interacting with mRNA of the gene, leading to expression inhibition [36], in this study, however, only those miRNAs were observed carefully, for which the value of mirSVR $\leq-0.8$. The use of such strict selection criteria made it possible to determine only those miRNAs, which may the most likely potentially negatively regulate expression of the analysed genes. When using the cut-off criterion, it was noted that 13 out of 39 miRNAs may regulate TNF- $\alpha$ expression: hsa-miR-599, hsa-miR-130a, hsa-miR-130b, hsa-miR-454, hsa-miR-301a, hsa-miR-301b, hsa-miR-19b, hsa-miR-19a, hsa-miR-181a, hsa-miR-181b, hsa-miR-181c, hsa-miR-181d, hsa-miR-150 and one molecule for TNFR1: hsa-miR-335 and TNFR2: hsa-miR-495. Consequently, it seems that an important issue which would make it possible to understand better the changes in the TNF- $\alpha$ expression during the therapy with the use of an anti-TNF medicine (adalimumab) in patients is to consider the role of the post-transcriptional mechanism of gene expression regulation by miRNAs [37-39]. The role of miRNA-130a, miR-454-3p in the negative regulation of TNF- $\alpha$ expression was confirmed by Huang et al., which coincides with our observation at the in silico level [40]. Moreover, it was observed that miR-301a (miRSVR -1.1996), belonging to the family of miR-130, engaged in the process of cell migration has got great potential to regulate TNF- $\alpha$ expression [41]. The role of hsa-miR-130a in proinflammatory processes and its effect on the expression profile of proinflammatory cytokines was confirmed by He et al., who observed its significant role in the intestine mucous membrane inflammation. The said authors state that the inhibition effect of the discussed molecule may constitute a new therapeutic strategy [42]. Basing on the bioinformatic tool used to search for miRNAs potentially regulating gene expression, it may be observed that hsamiR19a and hsa-miR19b molecules are engaged in the regulation of the TNF- $\alpha$ expression. The observations performed by us in silico coincide with those obtained by other groups of researchers, who described a lower expression of those molecules in patients with rheumatoid arthritis [43], and indicate their role in shaping the TNF- $\alpha$ expression profile $[44,45]$. The last large group of miRNAs involving the regulation of transcriptional activity of TNF- $\alpha$ is composed by 4 molecules belonging to the hsa-miR-181 family. Mir-181a is perceived as the marker of inflammatory response, the expression of which is correlated, among others, with TNF- $\alpha$ expression [46].
Moreover, hsa-miR-181a plays an important role in differentiating and maturing of the immunologic system cells [47]. In turn, mir-181 is described as a molecule playing a significant role in proapoptotic activity TNF- $\alpha$ [48]. Two miRNAs were identified in this paper, which the most likely participate in the regulation of expression TNFR1 receptors: hsa-miR-335, TNFR2: hsa-miR-495. Changes in the receptor expression profiles observed during the adalimumab therapy may also result from the changes in the expression profiles of the mentioned miRNAs during the anti-TNF therapy. The role of mir-335 in the preservation and maintenance of body homeostasis [49] and the role of tmiR-495 as a molecule participating in the immunologic response and apoptosis are emphasised [45, 50]. For that reason, the observed changes in the expression of TNFR1 and TNFR2, in correlation with the mRNA TNFactivity may indicate that the body strives to reach the balance and homeostasis.

\section{Conclusions}

The evaluation of the efficacy of the anti-TNF therapy with the use of molecular biology methods constitute an increasingly important tool that makes it possible to monitor the effects of therapy [51]. Moreover, the results obtained in our work also show that an individual variability must be taken into account when monitoring therapeutic effects at the transcriptome and proteome level in patients treated with adalimumab, as well as underline the essence of the epigenetic mechanism of RNA interference by miRNAs. The obtained results indicate an important role of introducing the changes in the cytokine expression profile as a supplementary diagnostic marker.

\section{Acknowledgments}

This research was financed by the Medical University of Silesia in Katowice/Poland on the basis of decision no. KNW-1-029/N/6/O. This research was supported in part by PLGrid Infrastructure.

\section{Conflict of interest}

The authors declare no conflict of interest.

\section{References}

1. Lubecka-Macura A, Kohut M. Nadrodzina TNF-mechanizmy działania, funkcje biologiczne i możliwości terapeutyczne. Gastroenterology Rev 2010; 5: 303-9.

2. Korobowicz A. Biologia czynnika martwicy nowotworów typu alfa (TNF- $\alpha$ ). Pol Merk Lek 2006; 124: 358-61.

3. Eder P, Łykowska-Szuber P, Stawczyk-Eder K, et al. Mechanizmy działania inhibitorów czynnika martwicy nowotworów $\alpha$. Gastroenterology Rev 2011; 6: 290-8.

4. Szechiński J. Enbrel. Zastosowanie kliniczne. Wydawnictwo Medyczne Górnicki, Wrocław, Poland 2008. 
5. Olszanecka-Glinianowicz M, Zahorska-Markiewicz B, Żurakowski A, et al. Rola czynnika martwicy nowotworów (TNF- $\alpha$ ) w kontroli metabolizmu. Wiad Lek 2005; 48: 11-2.

6. Gola J. Plejotropowe działanie TNF-alfa w chłoniakach nieziarniczych. Rozprawa doktorska. Wydział Farmaceutyczny z Oddziałem Medycyny Laboratoryjnej. Katowice SUM 2007.

7. Budzyński M, Grenda A, Filip A. Krążące mikrona - nowa klasa biomarkerów diagnostyczno-prognostycznych w przebiegu chorób nowotworowych. Post Biol Kom 2014; 41: 173 208.

8. Wcisło-Dziadecka D, Grabarek B, Zmarzły N, et al. Influence of adalimumab on the expression profile of genes associated with histaminergic system in the skin fibroblasts in vitro. BioMed Research Int 2018; 2018: 1582173.

9. Hawkes JE, Nguyen GH, Fujita M, et al. microRNAs in psoriasis. J Investig Dermatol 2016; 136: 365-71.

10. Huang RY, Li L, Wang MJ, et al. Exploration of the role of microRNAs in psoriasis: a systematic review of the literature. Medicine 2015; 94: e2030.

11. Neneman A, Adamski Z. Aspekty kliniczne i epidemiologiczne zaburzeń ogólnoustrojowych u chorych na łuszczycę. Forum Med Rodz 2009; 3: 447-53.

12. Romańska-Gocka K. Farmakoterapia łuszczycy. Ter Lek 2009; 65: 647-54.

13. Wcisło-Dziadecka D, Zbiciak M, Wcisło-Brzezińska L, Ma zurek U. Anti-cytokine therapy for psoriasis - not only TNF blockers. Overview of reports on the effectiveness of therapy with IL12/IL23 and T and B lymphocyte inhibitors. Post Hig Med Dosw 2016; 70: 1198-205.

14. Roda G, Jharap B, Neeraj N, Colombel JF. Loss of response to anti-TNFs: definition, epidemiology, and management. Clin Transl Gastroenterol 2016; 7: e135.

15. Pełka M, Broniarczyk-Dyła G. Zastosowanie leków biologicznych w dermatologii. Adv Dermatol Allergol 2007; 24: 35-41.

16. Szepietowski J, Adamski Z, Chodorowska G, et al. Leczenie łuszczycy - rekomendacje ekspertów Polskiego Towarzystwa Dermatologicznego Część druga: łuszczyca umiarkowana do ciężkiej. Dermatol Rev 2014; 101: 455-72.

17. Bosman FT, Yan P. Patologia molekularna raka jelita grubego. Pol J Pathol 2014; 65: 1-11

18. Lis K, Olga Kuzawińska, Bałkowiec-Iskra E. Tumor necrosis factor inhibitors - state of knowledge. Arch Med Sci 2014; 10: $1175-85$.

19. Wcisło-Dziadecka, Zbiciak-Nylec M, Brzezińska-Wcisło L, et al. Newer treatments of psoriasis regarding IL-23 inhibitors, phospodiesterase 4 inhibitors, and Janus kinase inhibitors. Derm Ter 2017; 30: 1-8.

20. Zänker M, Becher G, Arbach O, et al. Improved adalimumab dose decision with comprehensive diagnostics data. Clin Exp Rheumatol 2018; 36: 136-9.

21. Webb KC, Tung R, Winterfield LS, et al. Tumour necrosis factor-alpha inhibition can stabilize disease in progressive vitiligo. Br J Dermatol 2015; 173: 641-50.

22. SedgerMichael LM, McDermott MF. TNF and TNF-receptors: From mediators of cell death and inflammation to therapeutic giants - past, present and future. Cytokine Growth Factor Rev 2014; 25: 453-72.

23. Iborra M, Beltrán B, Bastida G, et al. Infliximab and adalimumab-induced psoriasis in Crohn's disease: a paradoxical side effect. J Crohns Colitis 2011; 5: 157-61.

24. Wang F, Schwarz BT, Graham WV, et al. IFN-gamma-induced TNFR2 expression is required for TNF-dependent intestinal epithelial barrier dysfunction. Gastroenterology 2006; 131: 1153-63.

25. Bosè F, Raeli L, Garutti C, et al. Dual role of anti-TNF therapy: enhancement of TCR-mediated T cell activation in peripheral blood and inhibition of inflammation in target tissues. Clin Immunol 2011; 139: 164-76.

26. Niemira M, Wiśniewska A, Mazerska Z. Polymorphism and the level of P450 gene expression in xenobiotic metabolism. Post Bioch 2009; 55: 279-89.

27. Rychlik-Sych M, Barańska M, Skrętowicz J. Clinical significance of pharmacogenetics in dermatological diseases. Przegl Lek 2012; 69: 120-4.

28. Czarnecka A, Niewiński P, Orzechowska-Juzwenko K, et al. Genotyp oksydacji CYP2D6 jako czynnik zwiększający ryzyko wystąpienia łuszczycy zwykłej. Derm Klin 2005; 7: 25-7.

29. Bornstein G, Lidar M, Langevitz P, et al. The prevalence and clinical effect of immunogenicity of TNF-alpha blockers in patients with axial spondyloarthritis. Clin Exp Rheumatol 2018; 36: 228-32.

30. Ovejero-Benito MC, Prieto-Pérez R, Llamas-Velasco M, et al. Polymorphisms associated with adalimumab and infliximab response in moderate-to-severe plaque psoriasis. Pharmacogenomics J 2018; 19: 7-16.

31. Papaconstantinou I, Kapizioni C, Legaki E, et al. Association of miR-146 rs2910164, miR-196a rs11614913, miR-221 rs113054794 and miR-224 rs188519172 polymorphisms with anti-TNF treatment response in a Greek population with Crohn's disease. World J Gastrointest Pharmacol Ther 2017; 8: 193-200.

32. Mansour AM. Adalimumab in the therapy of uveitis in childhood. Br J Ophthalmol 2007; 91: 274-76.

33. Bartelds GM, Krieckaert CL. Development of antidrug antibodies against adalimumab and association with disease activity and treatment failure during long-term follow-up. JAMA 2011; 305: 1460-8.

34. Shveta, Agarwal K, Chander R, Agarwal S. Serum levels of se-selectin, TNF-alpha and IL-1beta in patients of psoriasis before and after topical therapy in patients of psoriasis. IJCR 2017; 9: 55837-40.

35. Serefican H, Goksugur N, Bugdayci G, et al. Serum visfatin, adiponectin, and tumor necrosis factor alpha (TNF- $\alpha$ ) levels in patients with psoriasis and their correlation with disease severity. Acta Dermatolvenerol Croatia 2016; 24: 13-9.

36. Betel D, Wilson M, Gabow A, et al. The microRNA. org resource: targets and expression. Nucleic Acids Res 2008; 36 (Suppl 1): 149-53.

37. Cuppen BV, Rossato M, Fritsch-Stork RD, et al. Can baseline serum microRNAs predict response to TNF-alpha inhibitors in rheumatoid arthritis? Arthritis Res Ther 2016; 24: 189.

38. Raaby L, Langkilde A, Kjellerup RB, et al. Changes in mRNA expression precede changes in microRNA expression in lesional psoriatic skin during treatment with adalimumab. Br J Dermatol 2015; 173: 436-47.

39. Castro-Villegas C, Pérez-Sánchez C, Escudero A, et al. Circulating miRNAs as potential biomarkers of therapy effectiveness in rheumatoid arthritis patients treated with antiTNFalpha. Arthritis Res Ther 2015; 17: 49.

40. Huang HC, Yu HR, Huang LT, et al. miRNA-125b regulates TNF-alpha production in CD14+ neonatal monocytes via post-transcriptional regulation. J Leukoc Biol 2012; 92: 171-82.

41. Egawa $H$, Jingushi $K$, Hirono $T$, et al. miR-130 family promotes cell migration and invasion in bladder cancer through 
FAK and Akt phosphorylation by regulating PTEN. Sci Rep 2016; 3: 20574.

42. He C, Shi Y, Wu R, et al. miR-301a promotes intestinal mucosal inflammation through induction of IL-17A and TNF-alpha in IBD. Gut 2016; 65: 1938-50.

43. Krintel SB, Dehlendorff C, Hetland ML, et al. Prediction of treatment response to adalimumab: a double-blindn placebo-controlled study of circulating microRNA in patients with early rheumatoid arthritis. Pharmacogenomics J 2016; 16: 141-6.

44. Liu M, Wang Z, Yang S, et al. TNF-alpha is a novel target of miR-19a. Int J Oncol 2011; 38: 1013-22.

45. Chen B, She S, Li D, et al. Role of miR-19a targeting TNF- $\alpha$ in mediating ulcerative colitis. Scand I Gastroenterol 2013; 48: 815-24.

46. Xie W, Li Z, Li M, et al. miR-181a and inflammation: miRNA homeostasis response to inflammatory stimuli in vivo. Biochem Biophys Res Commun 2013; 430: 647-52.

47. Zhu J, Wang F, Wang H, et al. TNF-alpha mRNA is negatively regulated by microRNA-181a-5p in maturation of dendritic cells induced by high mobility group box-1 protein. Sci Rep 2017; 7: 12239.

48. Ghorbani S, Talebi F, Ghasemi S, et al. miR-181 interacts with signaling adaptor molecule DENN/MADD and enhances TNF-induced cell death. PLoS One 2017; 12: e0174368.

49. Tomé M, López-Romero P, Albo C, et al. miR-335 orchestrates cell proliferation, migration and differentiation in human mesenchymal stem cells. Cell Death Differ 2011; 18: 985-95.

50. Chen H, Wang X, Bai J, He A. Expression, regulation and function of miR-495 in healthy and tumor tissues. Oncol Lett 2017; 13: 2021-6.

51. Davis LS, Reimold AM. Transcriptional profiling of leukocytes from rheumatoid arthritis patients before and after anti-tumor necrosis factor therapy: a comparison of anti-nuclear antibody positive and negative subsets. Exp Ther Med 2017; 13: 2183-92. 